\title{
ETNOMATEMATIKA MELAYU: PERTAUTAN ANTARA MATEMATIKA DAN BUDAYA PADA MASYARAKAT MELAYU RIAU
}

\author{
Hasanuddin \\ Program studi pendidikan matematika, Universias Islam Negeri Sultan Syarif Kasim Riau \\ Jl. H. R. Soebrantas km 15,5 Tampan, Pekanbaru, Indonesia \\ e-mail: hasanuddin@uin-suska.ac.id
}

\begin{abstract}
Abstrak
Artikel ini bertujuan untuk mengeksplorasi unsur-unsur etnomatematika pada masyarakat melayu Riau. Hal ini penting, mengingat Propinsi Riau sedang mempersiapkan diri menjadi sebagai pusat kebudayaan Melayu. Oleh karena itu upaya penggalian, pengembangan dan pengenalan etnomatematika melayu Riau sangat diperlukan. Eksplorasi etnomatematika pada masyarakat melayu Riau menggunakan metode peneltian kulitatif-etnografis. Hasil penelitian ini menunjukkan banyaknya aktivitas etnomatematika dalam masyarakat melayu Riau. Pada artikel ini, disajikan berbagai aktivitas etnomatematika pada seni sastra, seni busana melayu, seni ukir dan aplikasi etnomatematika pada permainan masyarakat melayu Riau.
\end{abstract}

Kata kunci: Etnomatematika, melayu, riau, busana, seni sastra, seni ukir dan permainan rakyat

\section{PENDAHULUAN}

Matematika adalah formal sains. Matematika modern sangat patuh terhadap kaidah-kaidah yang sangat ketat dan menekan aturan yang sudah baku. Pada tahap perkembangannya, matematika modern menjadi cenderung eksklusif. Perkembangannya didasarkan pada pendekatan yang berlandaskan mantikisme dan formalisme, terutama untuk matematika murni. Oleh karena itu, matematika perlu mendapatkan sentuhan lain yang memunculkan keindahannya.

Keindahan matematika dapat ditemukan pada susunan, pola dan estika alam, bahkan budaya. Hardy (1940) menyatakan bahwa keindahan dalam matematika adalah yang utama, tidak ada tempat bagi matematika yang buruk. Matematika yang indah dapat ditemukan melalui artefak budaya. Misalnya pola-pola geometris yang ditemukan seni arsitektur (Abas, 2001), songket (Embong, Maizan, Aziz, \& Abd, 2010), dan anyaman (Gerdes, 2011). Pengaitan keindahan pola-pola geometris semacam ini dengan matematika bermuara pada pengaitan antara matematika dan budaya.

Matematika sebagai bagian dari budaya sudah diketahui oleh para antropolog, temuanya terbatas pada aritmatika pada budaya-budaya primitif (Wilder, 1950) Untuk memahami matematika sebagai bagian dari budaya, maka perlu dilihat pengaruh manusia terhadap matematika. Secara epistemik tidak ada perbedaan antara matematika dan ilmu lainnya (Prediger, 2003). Nilai yang terkandung dalam perilaku budaya manusia menunjukkan daya rasa estetis dan daya kreasi manusia (Nuh \& Dardiri, 2016). Pengaitan matematika dengan budaya harus digali berdasarkan kearifan lokal yang dimiliki oleh komunitas pemegang budaya.

Upaya ini dikenal dengan istilah Etnomatematika (Ubiratan D'Ambrosio, 1985). Lebih lanjut ia menyatakan bahwa:

"... Making a bridge between anthropologists and bistorians of culture and mathematicians is an important step towards recognizing that different modes of thoughts may lead to different forms of mathematics; this is the field which we may call ethnomathematics."(1985, p. 44)

Etnomatematika didasarkan pada kesadaran baru tentang pengenalan potensi diri masyarakat di bidang matematika. Selain itu, kurikulum matematika terlalu euro-sentris, dengan kata lain, konsep-konsep matematika yang ada terlalu berkiblat ke eropa. Dampaknya budaya lokal terkait matematika semakin terpinggirkan. Padahal setiap budaya lokal memiliki sejumlah kearifan yang terkait dengan matematika. Menurut D'Ambrosio:

"Ethnomathematics is the mathematics practiced by cultural groups, such as urban and rural communities, groups of workers, professional classes, children in a given age group, indigenous societies, and so many other groups that are identified by the 
objectives and traditions common to these groups."(Ubiratan D'Ambrosio, 2016, p. 1)

Jadi, etnomatematika adalah matematika yang dipraktekkan dalam kelompok-kelompok budaya, baik dari suku asli maupun kelas profesional. Dengan kata lain, setiap aktifitas budaya yang terkait dengan matematika dapat dipandang sebagai bagian dari etnomatematika.

Etnomatematika dapat ditemukan di berbagai belahan bumi, baik dari afrika, china maupun amerika. Sedangkan untuk wilayah asia pasifik dapat dilihat melalui kajian etnomatematika di papua nugini (Owens, 2012), suku kabihug di Filipina (Rubio, 2016), masyararakat tolaki di Sulawesi Tenggara, Indonesia (Sirate, 2011), masyarakat Sidoarjo (Rachmawati, 2012) dan aspek membilang pada masyarakat riau (Nuh \& Dardiri, 2016).

Etnomatematika dalam budaya melayu menurut Shaharir M. Zain (2002) menyatakan:

"Etnomatematika melayu sebagai matematika tinggalan tamadun melayu yang diajar, diucap, diujar, ditulis, dipakai dan dibaca dalam bahasa melayu dan mengikut nilai melayu." (2002, p. 97)

Melayu dalam pengertian yang disampaikan oleh Shaharer M. Zain adalah rumpun melayu yang ada di nusantara. Melayu Riau sebagai suatu komunitas masyarakat, tentu juga memiliki system pengetahuan yang belum tereksplorasi secara maksimal, terutama di bidang etnomatematika.

Sebagai salah satu provinsi yang berdekatan dengan Selat Melaka. Riau terus berbenah dan berupaya menjadi pusat kebudayaan melayu. Oleh karena itu, perlu dilakukan penggalian, pengembangan dan pengenalan seluruh potensi melayu Riau. Upaya ini melibatkan berbagai komponen masyarakat, akademisi dan budayawan. Upaya penggalian budaya melayu melalui penelusuran sumber tertulis maupun tak tertulis khususnya terkait dengan etnomatematika. Selanjutnya, pengembangan etnomatematika melayu dilakukan agar konsep-kosep yang terkandung dapat dieksplorasi lebih jauh. Setelah etnomatematika digali dan dikembangkan, maka perlu diperkenalkan kembali ke masyarakat. Upaya-upaya tersebut menggiring pada perlunya eksplorasi etnomatematika melayu Riau.

Penelitian tentang Etnomatematika pertama kali diperkenalkan pada tahun 1977 oleh
D'Ambrosio, seorang matematikawan Brasil pada tahun 1977. Definisi etnomatematika menurut D'Ambrosio adalah:

The prefix ethno is today accepted as a very broad term that refers to the socialcultural context and therefore includes language, jargon, and codes of behavior, myths, and symbols. The derivation of mathema is difficult, but tends to mean to explain, to know, to understand, and to do activities such as ciphering, measuring, classifying, inferring, and modeling. The suffix tics is derived from techné, and has the same root as technique (Rosa \& Orey 2011)

Di Indonesia, kajian tentang Etnomatematika masih relative baru. Berapa publikasi yang berkaitan dengan etnomatematika yaitu penelitian tentang etnomatematika masrakat sidoarjo (Inda Rachmawati:2012) dan studi kualitatif masyarakat Tolaki (Siti Sirate:2011). Adapun kajian tentang etnomatematika maelayu secara umum telah diperkenalkan oleh (Shahari M Zain: 2002). Oleh karena itu, Eksplorasi etnomatematika pada masyarakat melayu riau menjadi sangat penting.

\section{Kajian Literatur}

\section{Budaya}

Menurut KBBI daring, budaya adalah hasil pikir atau hasil akal budi (Badan Pengembangan dan Pembinaan Bahasa, 2016), tetapi secara definisi, budaya merupakan istilah yang sangat sulit untuk didefinisikan (Spenceroatey, 2012). Menurut Avruch (1998) salah satu opionir dalam kajian budaya yaitu Edward Tylor menulis tentang Primitive culture pada tahun 1870.

It is worth quoting Tylor's definition in its entirety; first because it became the foundational one for anthropology; and second because it partly explains why Kroeber and Kluckhohn found definitional fecundity by the early 1950s. Tylor's definition of culture is "that complex whole which includes knowledge, belief, art, morals, law, custom, and any other capabilities and habits acquired by man as a member of society”.(1998, p. 6)

Berdasarkan ilmu antropologi, budaya dapat didefinisikan sebagai keseluruhan sistem gagasan, tindakan, dan hasil karya manusia dalam rangka kehidupan masyarakat yang dijadikan milik diri manusia dengan belajar. (Koentjaraningrat, 1985). Jadi, dapat 
dikatakan bahwa hampir setiap aktivitas manusia merupakan budaya. oleh sebab itu, hampir setiap tindakan manusia dalam bermasyarakat tetap memerlukan proses pembelajaran. Berbeda pula di bidang sejarah, budaya diartikan sebagai tradisi atau warisan suatu masyarakat.

Kebudayaan terbagi ke dalam tujuh unsur dan dapat ditemukan pada setiap bangsa(Nuh \& Dardiri, 2016), meliputi:

a. Bahasa, dengan wujud ilmu komunikasi dan kesusteraan mencakup bahasa daerah, pantun, syair, novelnovel, dan lain sebagainya.

b. Sistem pengetahuan, meliputi science (ilmu-ilmu eksak) dan humanities (sastra, filsafat, sejarah, dsb).

c. Organisasi sosial, seperti upacaraupacara (kelahiran, pernikahan, kematian).

d. Sistem peralatan hidup dan teknologi, meliputi pakaian, makanan, alat-alat upacara, dan kemajuan teknologi lainnya.

e. Sistem mata pencaharian hidup.

f. Sistem religi, baik sistem keyakinan, dan gagasan tentang Tuhan, dewadewa, roh, neraka, surga, maupun berupa upacara adat maupun bendabenda suci dan benda-benda religius (candi dan patung nenek moyang) dan lainnya.

g. Kesenian, dapat berupa seni rupa (lukisan), seni pertunjukan (tari, musik,) seni teater (wayang), seni arsitektur (rumah, bangunan, perahu, candi, dsb), berupa benda-benda indah, atau kerajinan (2016, p. 225).

\section{Matematika sebagai Produk Budaya}

Matematika tumbuh dan berkembang di setiap belahan bumi. Pertumbuhan dan perkembangan ini dilatarbelakangi adanya tantangan hidup dengan latar belakang budaya yang berbeda. Setiap budaya dan atau subbudaya mengembangkan matematika dengan cara mereka sendiri. Hal ini mengakibatkan timbulnya perbedaan disetiap wilayah. Matematika yang dikembangkan pada masa kerajaan Romawi salah satunya adalah Angka Romawi, sedangkan Babilonia menghasilkan bilangan sexagesimal (bilangan basis 60$)$.

Matematika dipandang sebagai hasil akal budi manusia, selain itu ia juga dianggap sebagai hasil abstraksi pikiran manusia. Pemahaman tentang nilai-nilai dalam pembelajaran matematika belum menyentuh ke seluruh aspek. Selain itu, matematika hanya dipandang sebagai alat pemecahan masalah praktis saja. Sehingga, matematika hanya diajarkan seadanya saja, atau sebatas mengisi rutinitas pengajaran matematika saja.

\section{Riwayat dan Peta Masyarakat Melayu Riau}

Riau adalah sebuah provinsi di Indonesia yang terletak di bagian barat Indonesia dan bagian tengah pulau Sumatera. Secara geografis terletak di posisi $02^{\circ} 25^{\prime} \mathrm{LU}-01^{\circ} 15^{\circ}$ LS dan $100^{\circ} 03^{\prime}-104^{\circ} 00^{\prime}$ BT.

Luas wilayah provinsi Riau adalah $87.023,66 \mathrm{~km}^{2}$, yang membentang dari lereng Bukit Barisan hingga Selat Malaka. Riau memiliki iklim tropis basah dengan rata-rata curah hujan berkisar antara 2000-3000 milimeter per tahun, serta rata-rata hujan per tahun sekitar 160 hari.wilayah Riau terdiri dari 10 kabupaten dan 2 kota, 141 kecamatan dan 1517 desa /kelurahan. Jumlah penduduk provinsi Riau berdasarkan data Badan Pusat Statistik Provinsi Riau tahun 2010 sebesar 5.543.031 jiwa. Kabupaten/Kota yang memiliki jumlah penduduk terbanyak adalah Kota Pekanbaru dengan jumlah penduduk 903.902 jiwa, sedangkan Kabupaten/Kota dengan jumlah penduduk terkecil adalah Kabupaten Kepulauan Meranti yakni sebesar 176.371 jiwa.

Provinsi ini didiami oleh beragam suku bangsa, baik penduduk asli maupun pendatang. Salah satu penduduk asli Riau adalah melayu. Melayu tersebar disetiap kabupaten dan kota.

\section{Pengertian Etnomatematika}

Istilah ethnomathematics atau dalam bahasa indonesia disebut sebagai etnomatematika diperkenalkan oleh D'Ambrosio. Ia adalah seorang matematikawan Brasil yang sangat konsen terhadap perkembangan etnomatematika. 
Etnomatamatika dapat dipandang sebagai respon terhadap matematika barat yang terlalu eurosentris. Padahal menurut D'Ambrosio (1985) ada cara-cara berbeda dalam menginplementasikan matematika. Cara-cara tersebut harus mempertimbangan pengetahuan matematika yang dikembangkan oleh berbagai kelompok masyarakat. Selain itu, harus juga dipertimbangkan tujuan budaya dalam mempraktekkan matematika. baikcara mengelompokkan, berhitung, mengukur, merancang bangunan atau alat, maupun cara bermain dan lain sebagainya.

Pada awalnya etnomatematika dibentuk dari tiga kata yaitu ethno, mathema dan tics. Istilah "ethno" diartikan sebagai sesuatu yang sangat luas, mengacu pada konteks sosial budaya, termasuk bahasa, jargon, kode perilaku, mitos, dan symbol. Sedangkan "mathema" dapat diartikan dengan menjelaskan, mengetahui, memahami, dan melakukan kegiatan seperti pengkodean, mengukur, mengklasifikasi, menyimpulkan, dan pemodelan. Terakhir, "tics" berasal dari techne, dan bermakna sama seperti teknik.

Pada dasarnya istilah etnomatematika telah diperkenalkan oleh D'Ambrosio sejak lama. Ia telah menggunakan kata etnomatematika sebagai mode, gaya, dan teknik (tics) menjelaskan, memahami, dan menghadapi lingkungan alam dan budaya (mathema) dalam sistem budaya yang berbeda (ethnos). Ia menyatakan:

"I have been using the word ethnomathematics as modes, styles, and techniques (tics) of explanation, of understanding, and of coping with the natural and cultural environment (mathema) in distinct cultural systems (ethno)" (D'Ambrosio, 1999, 146).

Selanjutnya, D'Ambrosio (1985) menyatakan bahwa etnomatematika merupakan matematika yang dipraktekkan di antara kelompok budaya yang dapat diidentifikasi kelompok-kelompok budaya. baik dari perkumpulan paguyuban budaya, maupun kelas profesional. Ia menyatakan bahwa:

"The mathematics which is practiced among identifiable cultural groups such as national-tribe societies, labour groups, children of certain age brackets and professional classes" (1985, p. 45)
Istilah etnomatematika ini terus berkembang dinamis dan sangat cepat (Ubiratàn D'Ambrosio, 2016, p. 7). Sepanjang fakta-fakta baru, fenomena, situasi, dan permasalahan memerlukan etnomatematika, maka etnomatematika akan selalu ada. Saat ini, etnomatematika dipandang sebagai bagian dari sejarah matematika dan pendidikan matematika yang memiliki hubungan erat dengan antropologi dan kognitif sains kognitif (Ubiratan D'Ambrosio, 2016).

Definisi etnomatematika menurut D'Ambrosio adalah:

Ethnomathematics is the mathematics practiced by cultural groups, such as urban and rural communities, groups of workers, professional classes, children in a given age group, indigenous societies, and so many other groups that are identified by the objectives and traditions common to these groups. (Ubiratan D'Ambrosio, 2016, p. 1)

Jadi, etnomatematika dapat diartikan sebagai matematika yag dipraktikkan oleh suatu kelompok budaya, seperti masyarakat perkotaan dan pedesaan, kelompok buruh, anak-anak dari kelompok usia tertentu, masyarakat adat, dan lainnya.

Sebagai hasil dari perkembangan budaya yang berbeda, matematika memungkinkan memiliki bentuk yang berbeda dan sesuai dengan perkembangan kebutuhan masyarakat penggunanya. Secara umum, etnomatematika merupakan konsep matematika yang digunakan secara luas. Baik dalam aktivitas, rancang bangunan atau alat, bermain, menentukan lokasi, dan lain sebagainya.

\section{METODOLOGI}

Tujuan utama penelitian ini yaitu untuk mengeksplorasi unsur-unsur etnomatematika pada masyarakat melayu Riau.

Penelitian ini terdiri dari lima tahap, yaitu:

\section{Mengidentifikasi berbagai unsur} etnomatematika

Unsur unsur etnomatematika yang ada pada masyarakat melayu Riau.

\section{Menetapkan Informan}

Informan yang baik merupakan informan yang terlibat langsung serta mengetahui secara baik tentang hal yang akan dikaji. Informan yang dipilih dalam penelitian ini 
adalah orang-orang yang terlibat langsung dalam aktivitas etnomatematika.

1. Menggali informasi melalui Wawancara

Ada beberapa etika yang harus dipatuhi pewawancara, antara lain mempertimbangkan kepentingan informan terlebih dahulu, menyampaikan tujuan penelitian, melindungi privasi informan, dan jangan mengeksploitasi informan.

\section{Membuat Catatan Etnografis}

Sebuah catatan etnografis meliputi catatan lapangan, alat perekam gambar, artefak dan benda lain yang mendokumentasikan suasana budaya yang dipelajari.

3. Mengajukan Pertanyaan Deskriptif

Pertanyaan deskriptif merupakan pertanyaan yang membutuhkan jawaban penjelas.

\section{Melakukan Analisis Wawancara}

\section{Etnografis}

Analisis wawancara etnografis yaitu menggaris bawahi semua istilah asli informan yang telah diperoleh untuk mempertinggi peranannya dalam mengetahui tentang obyek budaya yang diteliti. Analisis ini dikaitkan dengan simbol dan makna yang disampaikan informan.

\section{Membuat Analisis Domain}

Peneliti membuat istilah pencakup dari apa yang dinyatakan informan. Istilah tersebut seharusnya memiliki hubungan semantis yang jelas.

\section{Mengajukan Pertanyaan Struktural}

Pertanyaan struktural merupakan pertanyaan yang disesuaikan dengan informan. Pertanyaan struktural bertujuan mengetahui bagaimana informan mengorganisir pengetahuan mereka.

\section{Melakukan Analisis Taksonomi}

Analisis taksonomi memusatkan perhatian pada domain tertentu yang sangat berguna untuk menggambarkan fenomena atau masalah yang menjadi sasaran penelitian. Analisis taksonomik dilakukan untuk membuat kategori dari simbol-simbol budaya yang ada pada kebudayaan yang diteliti.

\section{Menulis etnografi}

Peneliti kemudian memberikan penjelasan secara naratif mengenai esensi dari temuannya yang diteliti dan mendapatkan makna pengalaman informan.

\section{HASIL DAN PEMBAHASAN}

Aplikasi Etnomatematika dalam Masyarakat Melayu Riau

\section{Aplikasi Etnomatematika pada Seni Sastra}

Sastra merupakan kata serapan dari bahasa Sanskerta śástra, yang berarti "teks yang mengandung instruksi" atau "pedoman", dari kata dasar śās- yang berarti "instruksi" atau "ajaran". Dalam bahasa Indonesia kata ini biasa digunakan untuk merujuk kepada "kesusastraan" atau sebuah jenis tulisan yang memiliki arti atau keindahan tertentu (wikipedia).

Salah satu budaya melayu dalam dunia sastra yaitu berupa puisi lama. Puisi lama adalah puisi yang terikat oleh aturan-aturan, antara lain:

- Jumlah kata dalam 1 baris

- Jumlah baris dalam 1 bait

- Persajakan (rima)

- Banyak suku kata tiap baris

- Irama

\section{Pantun}

Pola matematika yang diterapkan pada jenis pantun yaitu bersajak a-b-a-b, tiap bait 4 baris, tiap baris terdiri dari 8-12 suku kata, 2 baris awal sebagai sampiran, 2 baris berikutnya sebagai isi. Contoh:

Kalau keladi sudab ditanam.

Janganlah lagi meminta talas.

Kalau budi sudah ditanam.

Janganlah lagi meminta balas

\section{Gurindam}

Gurindam merupakan puisi yang berbentuk bait 2 baris, bersajak a - a berisi nasihat. Sebagai puisi lama, gurindam merupakan pola pikir sebab-akibat yang dinyatakan dalam dua proposisi yang dihubungkan sebagai kalimat majemuk. Proposisi pertama biasanya merupakan sebab dan proposisi kedua merupakan akibat. Hubungan sebab akitab itu pada dasarnya merupakan hubungan yang ditandai dengan kata jika ..... maka .... Pada umumnya isi gurindam berkaitan dengan perbuatan atau aktivitas, baik aktivitas fisik maupun psikis 
Contoh:

Kurang pikir kurang siasat (a)

Tentu dirimu akan tersesat (a)

Barangsiapa tinggalkan sembahyang (b)

Bagai rumah tiada bertiang (b)

Jika suami tiada berhati lurus (c)

Istri pun kelak menjadi kurus (c)

Syair

Syair merupakan puisi yang memiliki ciri tiap bait 4 baris, bersajak a-a-a-a, berisi nasihat atau cerita. Contoh:

Pada zaman dabulu kala (a)

Tersebutlah sebuab cerita (a)

Sebuah negeri yang aman sentosa (a)

Dipimpin sang raja nan bijaksana (a)

\section{Talibun}

Talibun merupakan pantun genap yang tiap bait terdiri dari 6, 8, ataupun 10 baris. Contoh:

Kalau anak pergi ke pekan

Yu beli belanak pun beli

Ikan panjang beli dabulu

Kalau anak pergi berjalan

Ibu cari sanak pun cari isi

Induk semang cari dabulu

\section{Aplikasi Etnomatematika pada Rancangan Busana Melayu}

Etnomatematika juga dapat ditemui pada perancangan busana melayu., khususnya rancangan busanan cekak musang. Gambar ilustrasi pola dapat dilihat pada Gambar 1. Untuk labuh baju dibuat dengan dasar bentuk geometris persegi panjang, dengan pola-pola yang sejajar seperti $\mathrm{AB}=\mathrm{CD}$ yang diambil dari ukuran 1/2 lebar bahu. Sedangkan untuk labuh baju terdapat pola kesamaan $\mathrm{AD}=\mathrm{BC}$.

Selain itu terdapat beberapa rumusan untuk membentuk pola leher, untuk 1/2 lebar bukaan kerah baju

$\mathrm{MP}=\mathrm{DQ}=\mathrm{NO}=1 / 6$ lingkar leher $-1 / 4$ inci, Sedangkan untuk tinggi bukaan kerah diperoleh dengan rumusan

$\mathrm{DN}=\mathrm{QO}=1 / 6$ lingkar leher +1 inci

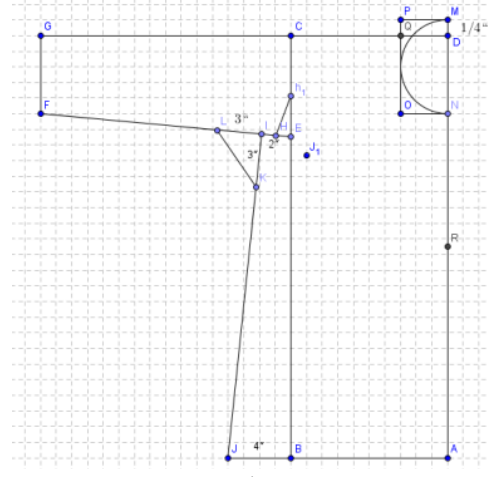

Gambar 1

Ketetangan:

$\mathrm{AB}=\mathrm{CD}=1 / 2$ lebar bahu

$\mathrm{AD}=\mathrm{BC}=$ labuh Baju

$\mathrm{CE} \quad=$ Lebar pangkal Lengan

$\mathrm{CG}=\mathrm{EF}=$ Labuh Lengan

GF $\quad=1 / 2$ Bukaan Tangan

$\mathrm{EH} \quad=1 / 2$ inci

$\mathrm{EB}=\mathrm{IJ} \quad=$ Panjang pesak

EI $=$ Lebar pesak atas (2 -2 1/2) inci (boleh ubah suai)

$\mathrm{BJ}=$ Lebar Pesak Bawah (4-4 1/2) inci (boleh ubah suai)

$\mathrm{IK}=\mathrm{IL} \quad=3$ inci ukuran kekek

$\mathrm{DM}=$ naikkan $1 / 4$ inci

$\mathrm{MP}=\mathrm{DQ}=\mathrm{NO}=1 / 6$ leher $-1 / 4$ inci

$\mathrm{DN}=\mathrm{QO}=1 / 6$ leher +1 inci

$\mathrm{NR}=1 / 2$ ukuran leher

Jadi, berdasarkan pada pemaparan dan ilustrasi di atas, dapat dilihat bahwa masyarkat melayu Riau telah mengaplikasikan konsepkonsep matematika dalam perancangan busana.

\section{Aplikasi Etnomatematika pada Seni Ukir}

Seni ukir adalah gambaran hiasan dengan bagian-bagian cekung dan cembung yang menyusun suatu gambar yang indah. Seni ukir di wilayah Riau memiliki beragam pola antara lain pucuk Rebung, awan larat, selembayung, lebah begayut, itik sekawan, singap/bidai, layanglayang dan kaluk pakis.

Pola-pola geometris yang dikembangkan dalam budaya masyarakat melayu Riau umumnya diserap dari alam. Lalu diterjemahkan kedalam pola-pola yang indah.

\section{Pucuk Rebung}

Pola geometris pucuk rebung pada dasarnnya berbentuk pola segitiga. Ketika diintegrasikan dengan seni ukir makan pola pucuk rebung akan menjadi sangat lentur dan indah. Pola pucuk rebung ini diambil dari pola tunas banmbu yang baru tumbuh. Beberapa contoh pola pucuk rebung dapat dilihat pada gambar berikut. 


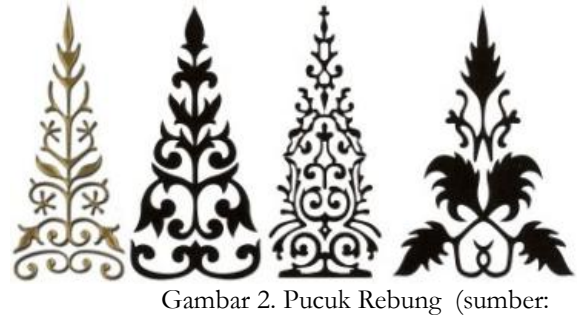

http://kedaimelayu.wordpress.com/2010/07/20/teater-malay/)

Aplikasi pola geometris pucuk rebung pada seni ukir dapat ditemui di setiap daerah yang berpenduduk melayu, akan tetapi motif pucuk rebung bisa berbeda antara daerah satu dengan yang lain.

\section{Awan Larat}

Pola geometris awan larat merupakan rangkaian dari motif yang tersusun rapi berdampingan dan berhuungan, awan larat dillhami oleh alam yaitu awan yang berarak ketika terbawa angin.

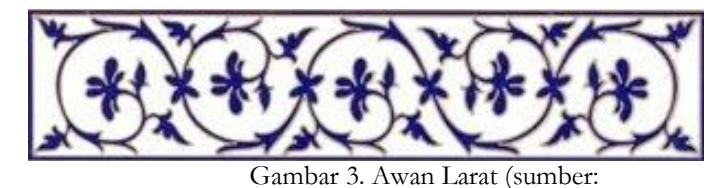

http://www.tamadunmelavu.info/2009/06/awan-larat-ragam-motifmelayu.html/)

Awan larat mengandung filosofi yaitu Batik berhias awan larat, lazim dipakai hiasan memanjang, rezeki tuah datang mendekat, cerita tiba duka pun hilang.

\section{Selembayung}

Selembayung adalah hiasan ukiran bersilangan yang terletak dikedua ujung perabung atap rumah. Selemayung memiliki makna sebagai mahkota rumah yang dapat membangkitkan cahaya suatu bangunan sehingga diletakkan di ujung perabung rumah. Beberapa makna selembayung rumah antara lain sebagai pekasih rumah, tajuk rumah, pasak atap, tangga dewa, rumah beradat, tuah rumah, lambang keperkasaan, lambang kasih sayang.

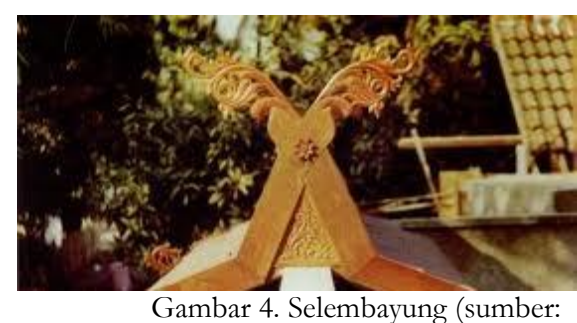

https://edita80.wordpress.com/2013/02/19/motif-dan-ukiranmelayu/

\section{Lebah begayut}

Pola geometris lebah begayut mencerminkan tetang rumah lebah madu yang biasanya menggantung dipohon. Lebah begayut ini terinspirasi dari bumi melayu yang sangat kaya akan pepeohonan besar yang sebagian dijadikan sebagai tempat mengantungnya rumah lebah.

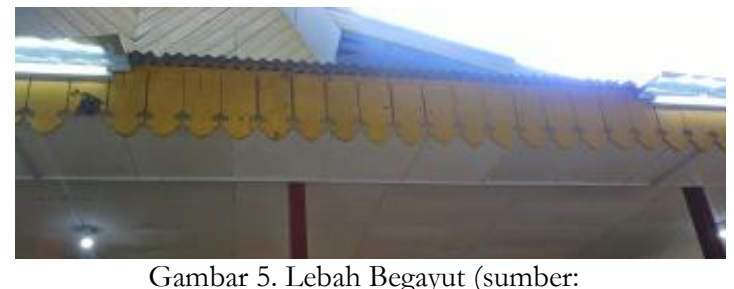

http://henyfiasri.blogspot.com/2014_06_01_archive.html)

\section{Semut beriring}

Pola geometris semut beriring terinspirasi dari hewan kecil semut yangselalu bekerjasama, mampu mengangkat barang-barnang yang jauh lebih besar dari badannya.

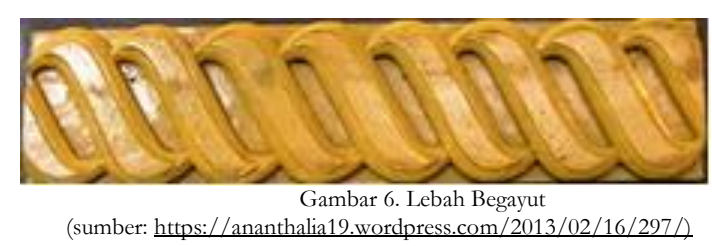

\section{Singap}

Singap bisa juga disebut bidai atau teban layar yaitu penutup yang berbentuk segitiga yang ipasang pada pada rumah bumbung panjang yang terbuka diujung depan dan belakang. Fungsi singap sebagai lubang angin bawah atap agar terjadi sirkulasi udara di dalam rumah.. Bidai memiliki tingkatan, bidai tingat satu, untuk orang biasa, bidai tingkat dua untuk rumah bangsawan dan bidai tingkat tiga untuk rumah keluarga raja.

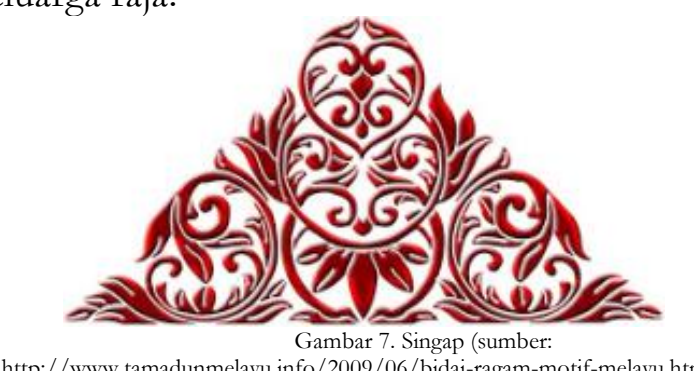

Sayap Layang-layang

Sayap layang layang diaplikasikan pada setiap sudut cucuran atap. Bentuknya mirip dengan selembayung. Setiap rumah yang 
berselembayung haruslah memeiliki sayap layang layang.

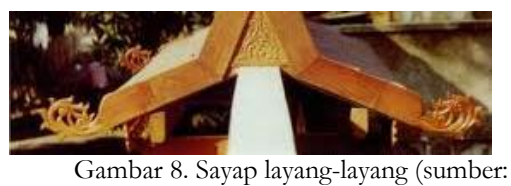

https://edita80.wordpress.com/2013/02/19/motif-dan-ukiran-melavu/)

\section{Kaluk Pakis}

Ukiran kaluk pakis biasanya diletakkan pada ukiran memanjang diterpakan pada tutup kaki dinding, daun pintu, lis dinding, tiang dan lis ventilasi.

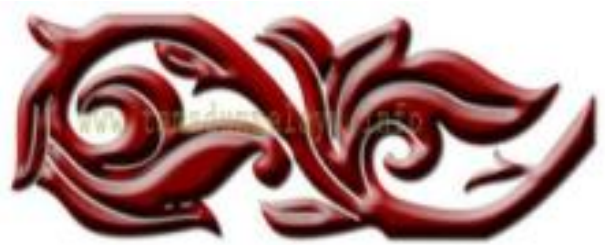

Gambar 9. Kaluk Pakis (sumber:http://www.slideshare.net/tikha12/motif-danukiran-melayu-riau-32086679)

\section{Aplikasi Etnomatematika pada Rancang Bangun Rumah}

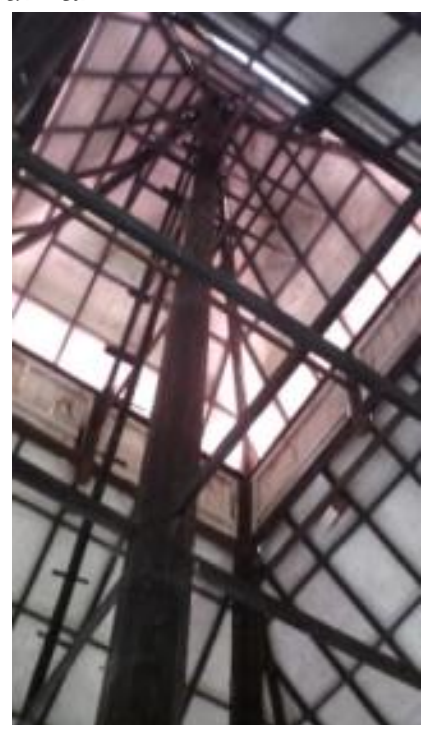

Gambar 10

\section{Aplikasi Etnomatematika Pada Pembuatan Perahu/sampan}

\section{Kapal Kayu Rokan Hilir}

Proses pembuatan kapal kayu di Rokan Hilir dilakukan sesuai dengan permintaan pemesan dengan memperhatikan ukuran panjang kapal, lebar kapal dan kedalaman kapal. Secara umu alur kerja pembuatan bagian bagian kapal kayu yaitu: penetapan ukuran, pemasangan, linggi, tinggi As,dan Gading-gading. Perencanaan pembuatan kapal tidak memerlukan gambar khusus. Penentuan rancangan hanya berdasarkan pengalaman dari kepala tukang. Sedangkan untuk menentukan kapasistas kapal, ditentukan berdasarkan ukuran lunas dan jumlah gadinggading serta jumlah lambung kulit kapal.

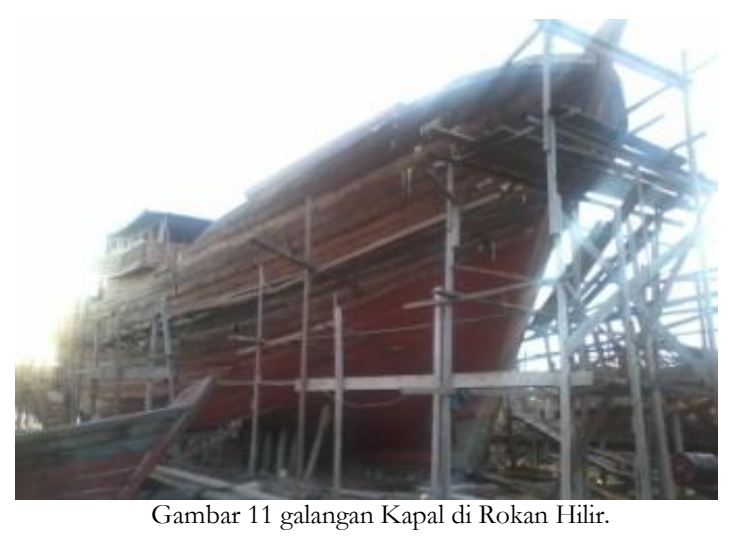

Sampan Leper di Indragiri Hilir

Sampan leper merupakan alat transportasi tradisional khas Indragiri Hilir. Sampan leper ini didisain untuk bisa digunakan di sungai dan meluncur di lumpur. Jadi desain lumpur bagian bawah didesain berbentuk datar.

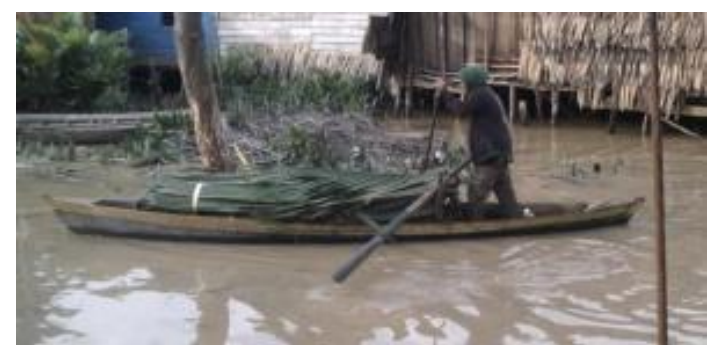

Gambar 12. Sampan Leper di sungai

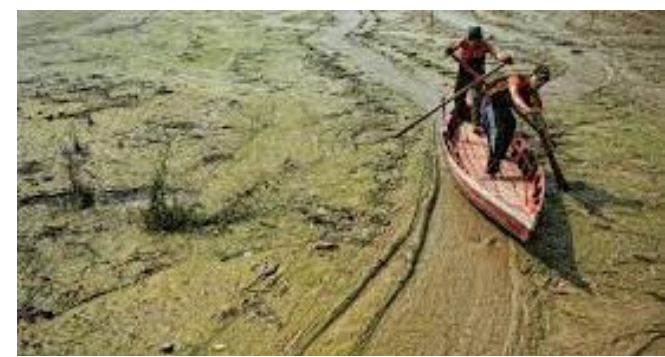

Gambar 13. Sampan Leper di lumpur

Sampan Kotak di Indragiri Hulu

Sampan kotak merupakan alat transportasi tradisional khas Indragiri Hulu. Pembuatan sampat kotak dilakukan ditepi sungai indragiri. Sampan kotak ini didesain untuk bisa digunakan 
mengangkut hasil panen petani. Bentuknya nya seperti kotak, sehingga bisa mengangkut banyak muatan.

Pembuatan sampan kotak tergantung permintaan, tidak teknik pengukuran khusus dalam pembuatan sampan kotak ini. Pembuatannya tergantung pengalaman dari kepala tukang.
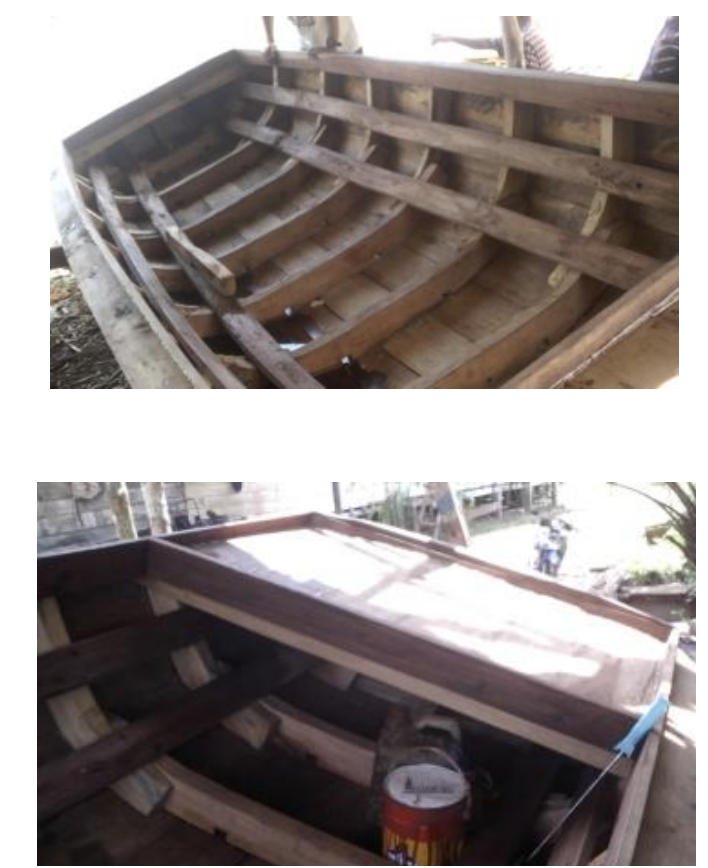

Gambar 14 model sampan kotak Khas Indragiri Hulu

\section{Jalur di Kuantan Sengingi}

Jalur merupakan sampan tradisional kuantan sengngi, jalur tidak dapat di buat begitu saja tanpa melalui berbagai proses baik yang menyangkut masalah tenaga ,biaya maupun yang menyangkut masalah teknis lainnya.

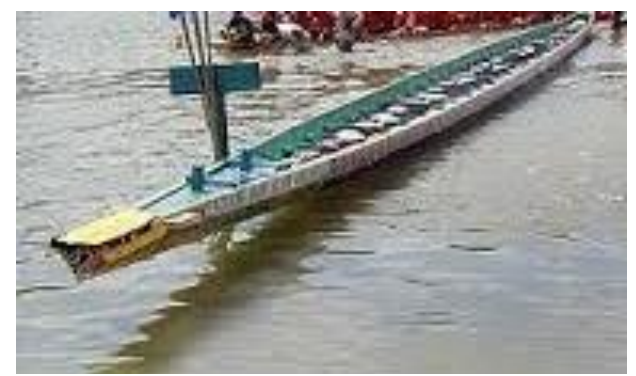

Gambar 15 Jalur

Pembuatan Jalur melalui berbagai proses yaitu: rampek kampung, mencari kayu, menobang kayu. Mengabung, melepas benang, pendadaan, mencaruk, menggaliak, membuat perut, membuat lubang kakok, .menggantung timbuku, membentuk halan kemudi, mengela, menghaluskan. Jalur didesain panjang agar dan lurus agar bisa memuat banyak orang dan untuk meminimalisir hambatan gerak pada saat pacu jalur.

\section{Etnomatematika dalam Permainan Rakyat Melayu Riau}

Adapun hasil eksplorasi juga menunjukkan terdapat beberapa permainan rakyat melayu. Terdapat berbagai pemikiran matematis dalam permainan rakyat.

\section{Permainan Congkak}

Permainan congkak adalah permainan yang juga dimainkan oleh masyarakat melayu Riau.

\section{Jumlah pemain} bergantian.

Setatak dimain oleh 2 orang secara

\section{Alat Permainan}

Alat permainan congkak berupa papan permainan yang terbuat dari kayu. Papan permainan congkak terdiri dari 16 buah lubang yang terdiri dari 14 lubang kecil dan dua lubang besar di sisi kiri dan kanan, lubang besar tersebut digunakan sebagai tempat mengumpulkan poin dalam permainan. Setiap 7 lubang kecil diisi dengan 7 buah biji, sedangkan bijinya terbuat dari biji-bijian, batu-batuan, kelereng atau biji plastik. Contoh gambar Congkak dapat dilihat pada Gambar 16. ss

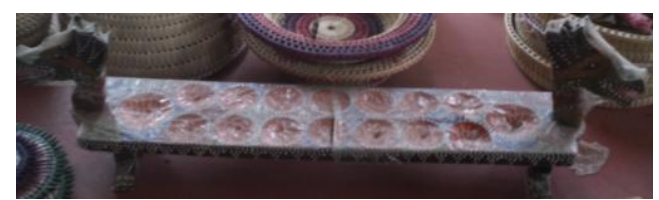

Gambar 16 Congkak yang dipamerkan oleh Dekranasda Indragiri Hilir

\section{Cara Bermain}

Tata cara dan urutan permainan setatak, sebagai berikut:

> Pada awal permainan setiap lubang kecil diisi dengan 7 (tujuh) buah biji. Total biji yang digunakan $7 \times 14=98$ biji.

$>$ Permainan dimulai dengan memilih lubang yang akan diambil dan meletakkan satu ke lubang di sebelah kanannya dan seterusnya. 
Pergerakan pendistribusia biji searah dengan jarum jam.

$>$ Jika dalam distribusi biji berakhir pada di lubang kecil yang berisi biji lainnya, maka pemain mengambil semua biji-biji lalu mendistribusikan kembali searah jarum jam.

$>$ Jika dalam distibusi biji berakhir di lubang besar, maka pemain melanjutkan permainan dengan memilih lubang kecil untuk didistribusikan kembali.

> Jika dalam disribusi biji habis di lubang kecil di sisinya maka berhenti berhenti dan mengambil seluruh biji di sisi yang berhadapan.

> Jika dalam disribusi biji berhenti di lubang kosong di sisi lawan maka pemain berhenti dan digantikan oleh pemain lawan.

$>$ Permainan selesai jika seluruh biji sudah masuk ke lubang besar kedua pemain.

$>$ Pemenangnya adalah pemain yang mendapatkan biji terbanyak.

\section{Aspek Etnomatematika dalam Permainan Congkak}

Aspek etnomatematika dalam permainan congkak dapat dilihat dari ide-ide matematika yang terkandung dalam permainan:

\section{$\checkmark$ Operasi Aritmatika}

Aspek etnomatematika yang ada pada permainan congkak antara lain:

Penjumlahan, setiap biji yang didistribusikan di lubang, berarti terjadi penjumlahan yang akan menentukan skor akhir dari permainan. Hal ini dapat menjadi media pberhitung bagi masyarakat melayu.

Pengurangan, setiap biji yang didistribusi pada setiap lubang berarti terjadi pengurangan biji yang ada di tangan.

Perkalian, setiap lubang kecil diisi dengan 7 (tujuh) biji artinya terjadi perkalian yaitu $7 \mathrm{x}$ $7 \times 2=98$.

Pembagian, jumlah seluruh biji yang digunakan dalam permainan sebanyak 98 biji dibagi rata kedua pemain. $98: 2=49$.

\section{$\checkmark$ Modular}

Permainan congkak sangat erat kaitannya dengan sistem modulo. Hal ini dapat dilihat ketika pemain ingin mengetahui dimana posisi meletakkan biji terakhir yang ada di tangan.

Contoh:
Misalkan anda Memiliki 21 biji pada lubang nomor 2. Jika pemain menaburkan satu persatu biji ke dalam lubang yang diambil dari lubang nomor dua, dimanakah lubang tempat meletakan biji terakhir?

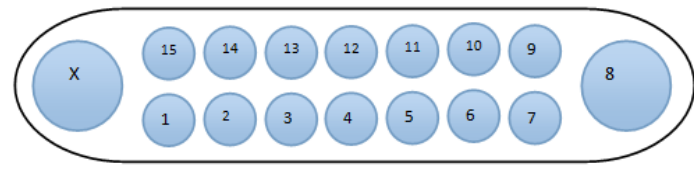

Gambar 17 Nomor posisi Lubang

Untuk menyelesaikan persoalan ini pemain menerapkan konsep modulo dengan menjumlah nomor urutan lubang dengan 21 mod 15. Ilustrasi dapat dilihat pada gambar berikut

Posisi Awal

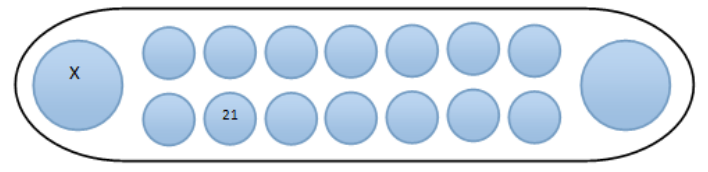

Posisi Akhir

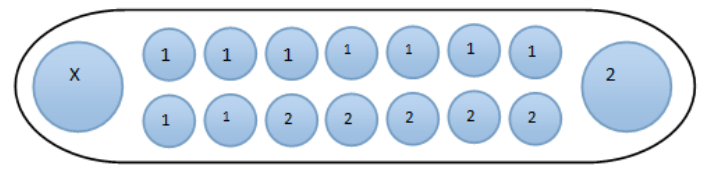

biji terakhir yang ditangan akan diletakkan dengan mengikuti aturan

$2+(21 \bmod 15)=2+6=8$

Jadi, biji terakhir akan diletakkan pada lubang nomor 8 atau lubang besar.

\section{Permainan Setatak}

Permainan setatak permainan yang ditemui di daerah propinsi riau, berdasarkan pada penuturan narasumber $H$. Raja Indra Kelana, Pengurus Lembaga Adat Melayu Riau, kabupaten Indragiri Hilir Riau bahwa permainan ini merupakan permainan rakyat yang dimainkan oleh anak di kabupaten Indragiri Hilir.

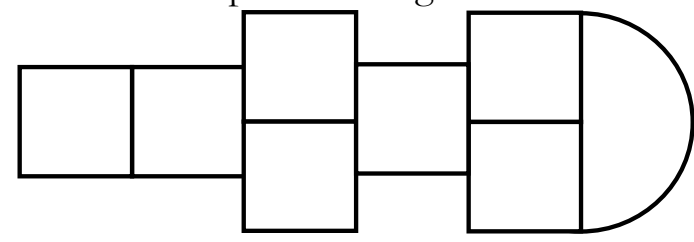

Gambar 18. Pola Setatak 
Permainan rakyat Riau ini memiliki kaitan erat dengan matematika, hal ini dapat dilihat dari bangun-bangun geometri yang dijadikan arena permainan. Bentuk-bentuk geometris yang diperoleh atara lain persegi, dan atau persegi panjang serta setengah lingkaran atau setengah elips.

\section{Jumlah Pemain}

Setatak dimain oleh minimal 2 - 5 orang secara bergantian.

\section{Alat Permainan}

Alat permainan setatak ada terdiri dari dua jenis yaitu:

\section{$\checkmark$ Arena Bermain}

Arena bermain berupa pola geometris yang digambar di lapangan atau tanah.

\section{$\checkmark$ Gacuk (Ucak)}

Gacuk atau ucak adalah benda pipih berbentuk bulat. Ucak ini bisa dibuat dari plastik tebal, pecahan piring yang di tumpulkan tepinya agar tidak membahayakan.

\section{Cara Bermain}

Tata cara dan urutan permainan setatak, sebagai berikut:

$>$ Pemain melewati arena setatak dengan cara berjingkat, dan meloncat sebelah kaki.

$>$ Kaki dan tangan tak boleh menyentuh garis setatak.

$>$ Petak yang ada ucak, tidak boleh diinjak, tetapi harus dilompati.

$>$ Setiap selesai satu ronde, pemain mengambil bintang.

> Pengambilan bintang dilakukan dengan cara berdiri membelakangi arena dibawah petak satu, lalu melempar ucak ke belakang, petak tempat jatuh ucak menjadi milik dengan menandai tanda bintang.

$>$ Petak yang telah diberi bintang, boleh diinjak dengan dua kaki oleh pemiliknya, tetapi tidak boleh diinjak oleh lawan.

\section{Aspek Etnomatematika dalam permainan Setatak}

Aspek etnomatematika dalam permainan setatak dapat dilihat dari ide-ide matematika yang terkandung dalam permainan:

\section{$\checkmark$ Bangun Datar}

Pada permainan setatak, pemain harus menggambar pola geometri matematika terlebih dahulu. Pola-pola geometri seperti yang terlihat pada Gambar 19 terdiri dari bangun datar persegi dan setengah lingkaran.

Bangun datar: Persegi

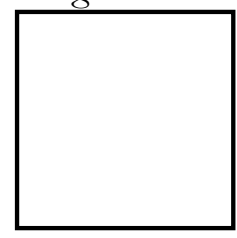

Bangun datar: Setengah Lingkaran

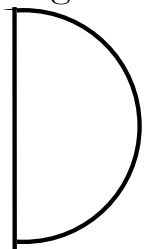

\section{$\checkmark$ Konsep Simetris}

Arena permainan dibangun dengan memanfaatkan bangun-bangun geometri yang simetris.

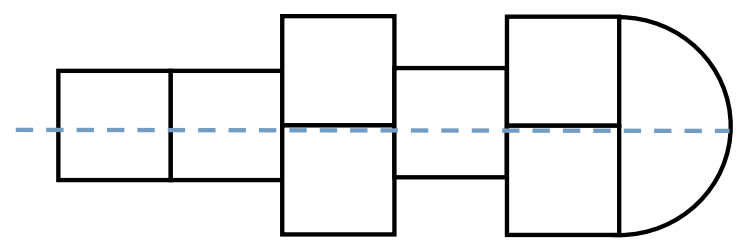

Gambar 19 Bentuk simetri pada permainan setatak

\section{$\checkmark \quad$ Logika Matematika}

Permainan setatak memuat logika matematika, yaitu konsep benar-salah. Petak yang tidak ada tanda bintang boleh diinjak oleh pihak lawan, sedangkan petak yang ada petak tidak boleh dinjak. Apabila ketentuan tersebut dilanggar maka pemain digantikan oleh pihak lawan.

\section{Permainan Patok Lele}

Salah satu permainan tradisional yang dimainkan oleh masyarkat melayu riau yaitu Patok Lele. Permainan ini adalah permainan rakyat. Permainan ini memiliki nama yang berbeda di beberapa wilayah Riau, misal: tuk lele (Pekanbaru) dan kelele (Pelalawan).

Permainan ini dilaksanakan pada satu 
sore hari, setelah selesai sholat subuh, malam bulan purnama dan setalah sholat di bulan bulan ramadhan. Adapun tempat pelaksanaan permainan ini yaitu di lapangan dekat rumah atau di jalan yang agak luas depan rumah.

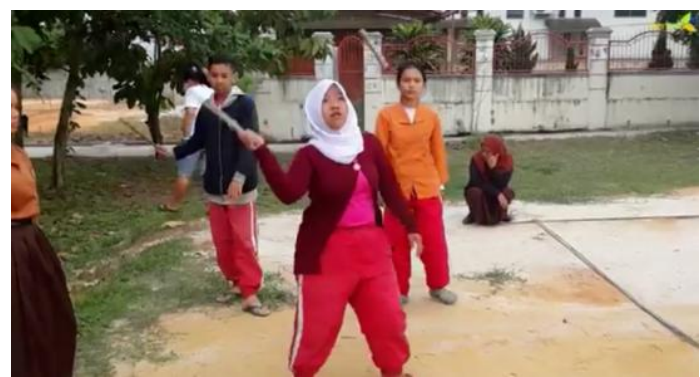

Gambar 20 Permainan Petok Lele (sumber: Youtube)

\section{Jumlab Pemain:}

Pada umumnya, patok lele dimainkan oleh 4 (empat) orang, tepai bisa juga dimainkan oleh 2 (dua) orang saja.

\section{Alat Bermain:}

$\checkmark$ Anak patok lele, terbuat dari kayu bulat kecil dengan ketebalan $\pm 3 \mathrm{~cm}$ dengan panjang $\pm 15 \mathrm{~cm}$.

$\checkmark$ Pengungkit (sekaligus pemukul), terbuat dari kayu yang sama dengan panjang maksimum $40 \mathrm{~cm}$.

$\checkmark$ Lubangi tanah dengan arah memanjang sepanjang ukuran anak patok lele $(15 \mathrm{~cm})$ dengan lebar seukuran anakpatok lele tadi.

\section{Cara bermain:}

$\checkmark \quad$ Letakkan posisi miring 15 derajat hingga 45 derajat.

$\checkmark$ Pukul ujung anak patok lele dengan pengungkit hingga terangkat ke atas.

$\checkmark$ Lambungkan beberapa kali dengan memukul beberapa kali dari bawah. Ulangi lagi jika masih memungkinkan, ungkit lagi hingga 3 kali atau lebih. Setelah itu Anda pasang kuda-kuda untuk memukul anak patok lele tadi sejauh mungkin.

$\checkmark$ Permainan dimulai dengan mengungkit anak patok lele sejauh-jauhnya. Anak Patok Lele itu berusaha ditangkap oleh tim lawan yang berdiri jauh.

$\checkmark$ Jika anak patok lele tadi tertangkap, maka giliran tim lawan yang melakukan pengungkitan. Tapi jika lawan Anda tidak mampu menangkap anak patok lele tadi maka dia masih berhak melemparkan anak patok lele tadi ke induknya (yakni tuas pengungkit atau pemukul tadi) yang posisinya melintang di atas lubang untuk anak patok lele diungkit tadi.

$\checkmark$ Jika dalam lemparan ke induknya itu mengenai tuas tadi berarti lawan Anda yang memperoleh giliran mengungkit. Begitu seterusnya bertukar jika Anda yang menjadi pelempar (bukan pengungkit).

$\checkmark$ Permainan ini berakhir jika total pukuran Anda paling tinggi nilainya karena dikalikan 2, 3 atau 4 kali dalam setiap pukulan terhadap anak patok lele.

Aspek Etnomatematika dalam Permainan Patok Lele

Aspek etnomatematika dalam permainan patok lele dapat dilihat dari ide-ide matematika yang terkandung dalam permainan:

\section{$\checkmark$ Pengukuran}

Aktivitas pengukuran dilakukan oleh pemain dengan menggunakan tongkat pengungkit. Satuan panjang ukuran yang yang digunakan adalah satuan panjang pengungkit. Yang dinilai adalah jarak antara lubang tempat mengungkit anak lele dengan tempat jatuhnya anak lele.

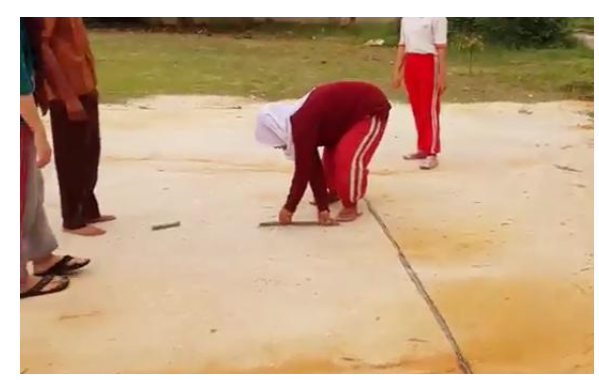

Gambar 21 Aktivitas Mengukur (sumber: Youtube)

\section{$\checkmark$ Penjumlaban}

Aspek penjumalah dalam permainan ini diperoleh dari Penjumlahan nilai yang didapat pada setiap langkah permainan.

\section{$\checkmark$ Perkalian}

Aspek perkalian yang muncul dalam perkalian ini diperoleh dari jumlah pukulan dikalikan dengan jarak lubang tempat 
mengungkit dengan tempat jatuhnya anak lele.

\section{Kelipatan}

Pemain ini juga melibatkan aspek kelipatan. Pemain akan terkesan dengan gagasan kelipatan yang bisa muncul dalam permaian ini antara lain

$$
\begin{aligned}
& 2,4,6,8,10,12,14,16,18, \ldots \\
& 3,6,9,12,15,18,21,24,27, \ldots \\
& 4,8,12,16,20,24,28,32,36, \ldots
\end{aligned}
$$

\section{$\checkmark$ Perbandingan}

Konsep perbandingan diperoleh dengan membanding nilai yang diperoleh setiap tim dengan batas permainan, tim pemenang ditentukan dengan melihat tim mana yang terlebih dahulu melewati nilai tertentu atau batas skor permainan.

\section{Ilustrasi:}

Misalkan $n$ adalah jumlah pukulan dan $p$ adalah satuan panjang pengungkit, Maka nilai yang diperoleh adalah

Dengan i jarak dalam

$$
\text { Nilai }=n \times \mathrm{i}
$$

Contoh:

Seorang pemain patok lele dapat mengungkit hingga 3 kali anak patok lele, lalu memukul sejauh 12 Panjang Pengungkit, maka nilai yang diperoleh adalah

$$
\begin{aligned}
\text { Nilai } & =n \times i \\
& \\
& =3 \times 12 \mathrm{p} \\
& =36
\end{aligned}
$$

\section{Ilustrasi:}

Pemenang permainan diperoleh apabila nilai tim A [nilai(A)] atau nilai tim B [nilai(B)] lebih besar atau sama dengan nilai kesapakatan batas permainan [nilai(M)], ilustrasi matematikanya

$$
\text { Jika Nilai(A) } \geqq \operatorname{Nilai}(M) \text { dan Nilai(B) }
$$$$
\text { Nilai(M), maka pemenangnya adalah Tim }
$$$$
\text { A, }
$$

Jika Nilai(B) $\geqq$ Nilai(M) dan Nilai(A) $\leqq$ Nilai(M), maka pemenangnya adalah Tim B

Contoh:
Nilai batas permainan adalah 200p, sedangkan perolehan angka Tim A sebanyak 198 p dan Tim B memperoleh nilai $201 p$.

Karena

$\operatorname{Nilai}(\mathrm{A})=201 p \geqq 200 p=\operatorname{Nilai}(\mathrm{M})$ dan Nilai(B) $=198 p \leqq 200 p=\operatorname{Nilai}(M)$

Maka pemenangnya adalah Tim A.

\section{KESIMPULAN}

Aktivitas etnomatematika pada masyarakat melayu Riau sangat beragam. Mulai dari membilang, mengukur, dan berbagai aplikasi dalam seni sastra, seni busana, seni ukir, seni rancang bangun kapal dan permainan rakyat.

\section{PENGHARGAAN}

Artikel adalah bagian dari penelitian tentang Eksplorasi Etnomatematika pada Masyarakat Melayu Riau, yang terlaksana atas kerja sama antara Institut for Souteast Asia Islamic Studies dan Balai Penelitian Provinsi Riau

\section{REFERENSI}

Abas, S. J. (2001). Islamic Geometrical Patterns for the Teaching of Mathematics of Symmetry. Symmetry: Culture and Science, 12(1-2), 53-65.

Avruch, K. (1998). Culture and Conflict Resolution. Washinton, DC: United States Institute of Peace Press. Retrieved from https://books.google.co.id/books?id=Oof mUheyGJAC\&pg $=\mathrm{PA} 39 \& \mathrm{hl}=\mathrm{id} \&$ source $=$ gbs_toc_r\&cad $=3 \#_{\mathrm{v}}=$ onepage $\& \mathrm{q} \& \mathrm{f}=$ false

Badan Pengembangan dan Pembinaan Bahasa, K. P. dan K. R. I. (2016). Budaya. Retrieved from https://kbbi.kemdikbud.go.id/entri/buday a

D'Ambrosio, U. (1985). Ethnomathematics and its Place in the History and Pedagogy of Mathematics. For the Learning of Mathematics, 5(1), 44-48.

D'Ambrosio, U. (2016). An Overview of the History of Ethnomathematics. In M. Rosa, U. D’Ambrosio, D. C. Orey, L. Shirley, W. V. Alangui, P. Palhares, \& M. E. Gavarrete (Eds.), Current and Future Perspectives of Ethnomathematics as a Program (pp. 5-11). Springer International Publishing. 
https://doi.org/10.1007/978-3-319-301204

D’Ambrosio, U. (2016). Ethnomathematics: Link between Traditions and Modernity. ROTTERDAM / TAIPEI: SENSE PUBLISHERS.

Embong, R., Maizan, N., Aziz, A., \& Abd, Z. (2010). An Insight into the Mathematical Thinking of the Malay Songket Weavers. Procedia - Social and Behavioral Sciences, 8(5), 713-720.

https://doi.org/10.1016/j.sbspro.2010.12. 099

Gerdes, P. (2011). African Basketry: Interweaving Art and Mathematics in Mozambique. In Bridges Coimbra Mathematics, Music, Art, Architecture, Culture Conference Proceedings (pp. 9-16).

Hardy, G. H. (1940). A Mathematician's Apology. Edmonotn, Canada: University of Alberta Mathematical Sciences Society.

Nuh, Z. M., \& Dardiri. (2016). Etnomatematika dalam Sistem Pembilangan pada Masyarakat Melayu Riau. Kutubkhanah: Jurnal Penelitian Sosial Keagamaan, 19(2), 220238.

Owens, K. (2012). Identity and Ethnomathematics Projects in Papua New Guinea An Ecocultural Pedagogy of Mathematics. In J. Dindyal, L. P. Cheng, \& S. F. $\mathrm{Ng}$ (Eds.), Mathematics education: Expanding horizons (pp. 586-593). Singapore: Mathematics Education Research Group of Australasia Inc.

Prediger, S. (2003). Mathematics - Cultural Product or Epistemic Exception? In B. Lowe, V. Peckhaus, \& T. Raasch (Eds.), The History of the Concept of the Formal Sciences Papers (pp. 217-232). Bonn.

Rachmawati, I. (2012). Eksplorasi Etnomatematika Masyarakat Sidoarjo. MATHUnesa, 1(1).

Rubio, J. S. (2016). The Ethnomathematics of the Kabihug Tribe in Jose Panganiban, Camarines Norte, Philippines. Malaysian Journal of Mathematical Sciences, 10, 211-231.

Sirate, S. F. S. (2011). Studi Kualitatif tentang Aktivitas Etnomatematika dalam Kehidupan Masyarakat Tolaki. LENTERA PENDIDIKAN, 14(2), 123-136.

Spencer-oatey, H. (2012). What is Culture ? A
Compilation of Quotations. GlobalPAD Open House. Retrieved from http://www.warwick.ac.uk/globalpadinterc ultural

Wilder, R. L. (1950). The Cultural Basis of Mathematics. In Proceedings International Congress of Mathematicians (pp. 258-271).

Zein, S. M. (2002). Etnomatematik Melayu. SARI: Jurnal Alam Dan Tamadun Melayu, 20, 97-112.

Website:

http://kedaimelayu.wordpress.com/2010/07/20/tea ter-malay/

http://www.tamadunmelayu.info/2009/06/awanlarat-ragam-motif-melayu.html/

https://edita80.wordpress.com/2013/02/19/motifdan-ukiran-melayu/

http://henyfiasri.blogspot.com/2014_06_01_archive .html

https://ananthalia19.wordpress.com/2013/02/16/2 $97 /)$

http://www.tamadunmelayu.info/2009/06/bidairagam-motif-melayu.html)

https://edita80.wordpress.com/2013/02/19/motifdan-ukiran-melayu/

http://www.slideshare.net/tikha12/motif-danukiran-melayu-riau-32086679

Riau Heritage. Permainan patok lele. https://www.youtube.com/watch?v $=$ avwzsR RfL9g 